\title{
A rare Localization of Mixoma: Originating in the Right Atrial Septum
}

\author{
Seçkin Dereli ${ }^{1}$, Melih Ürkmez ${ }^{2}$, Kaptanı- Derya Tayfur ${ }^{3}$, Mustafa Yenerçağ ${ }^{1}$, Ahmet Kaya ${ }^{1}$, Mehmet Filiz $^{1}$ \\ ${ }^{1}$ Department of Cardiology, Ordu University Medical School, Ordu, Turkey \\ ${ }^{2}$ Department of Cardiavascular Surgery, Ordu State Hospital, Ordu, Turkey \\ ${ }^{3}$ Department of Cardiavascular Surgery, Ordu University Medical School, İstanbul, Turkey
}

Received: 25 August 2020, Accepted: 27 November 2020, Published online: 31 December 2020

(C) Ordu University Institute of Health Sciences, Turkey, 2020

\begin{abstract}
Myxoma is the most common bening cardiac tumourt. Approximately $75-80 \%$ of cardiac myxomas are located in the left atrium. The most common non-specific symptoms are such as shortness of breath, syncope. A 74-year-old female patient was admitted to our outpatient clinic with shortness of breath and chest pain, in the echocardiography showed a mobile mass in the right atrium. The patient, whose diagnosis of myxoma was confirmed by trans esophageal echocardiography, underwent intracardiac mass excision. Because the right atrial myxomas are rare, we wanted to present our patient. An underlying cardiac pathology should be kept in mind in patients presenting with symptoms such as non-specific breathlessness
\end{abstract}

Key words: Right atrial myxoma, cardiac tumour, dyspnea

Suggested Citation: Dereli S, Urkmez M, Tayfur K-D, Yenercag M, Kaya A, Filiz M. A rare localization of mixoma: Originating in the right atrial septum. Middle Black Sea Journal of Health Science, 2020; 6(2):404-406.

\section{Address for correspondence/reprints:}

Seçkin Dereli

Telephone number: +90 (533) 3760984

ORCID-ID 0000-0003-0090-3835

E-mail: drseckindereli@gmail.com

DOI: $10.19127 / \mathrm{mbsjohs} .785106$

Note: A part of this study was presented as "Poster Presentation" at the "16th International Eastern Mediterranean Family Medicine Congress (11-14 May 2017)".

\section{Introduction}

Myxoma is primary cardiac tumor wich is bening character and occurs in the left atrium in more than $75 \%$ of patients. As an atypical location, the right heart location is observed in about $10-15 \%$ of cases and its clinical presentation is not specific. Although it is rare in tumors located in the right heart, it is known that the incidence of pulmonary embolism increases. (Shapiro 2001; Lepillier et al, 2010; Kaya et al, 2014).

Myxomas can be seen in almost any age group, but it is known to be detected most frequently after the third decade. The symptoms and findings detected in patients vary according to the localization of the tumor. Left atrial myxomas may present with dyspnea, syncope with the movement due to mitral obstruction and systemic emboli. It may show symptoms of right heart failure in the right heart and 
cause pulmonary embolism (Castillo and Silvay 2010; Veicki et al. 2010)

In patients with progressive shortness of breath with no underlying cause or embolic pathologies for which no possible cause can be found should be caution exercised in terms of the possibility of intracardiac tumor. We presented to a patient with right atrial mixomas which is rare who applied to different outpatient clinics for several months with shortness of breath.

\section{Case}

A 67-year-old female patient was brought directly to A 74-year-old female patient was admitted to our clinic with atypical chest pain and dyspnea for about a month. The patient's dyspnea was independent of effort and was more severe over the past week. She had previously known hypertensionwith- out atherosclerotic risk factors. On his physical examination, blood pressure and heart rate were 120/ $80 \mathrm{mmHg}$ and $95 \mathrm{bpm}$, respectively. Heart and respiratory auscultation findings were normal except for 2/6 systolic murmur, which was heard maximally at the left parasternal region. Electrocardiogram showed sinus rhythm and right bundle branch block. Transthoracic echocardiography showed normal left ventricular systolic function (ejection fraction: 65\%) and mass on the rigt atrial septum (Figure. A). For a more accurate assessment, we performed a transesophageal echocardiography, which showed a mobile $2.1 \times 1,2 \mathrm{~cm}$ mass origination in the right atrial septum with a handle. Because of its mobility and the risk of embolization, the mass was surgically (Figure. B) removed. The histological findings showed myxoma. The patient was discharged uneventfully after the operation.

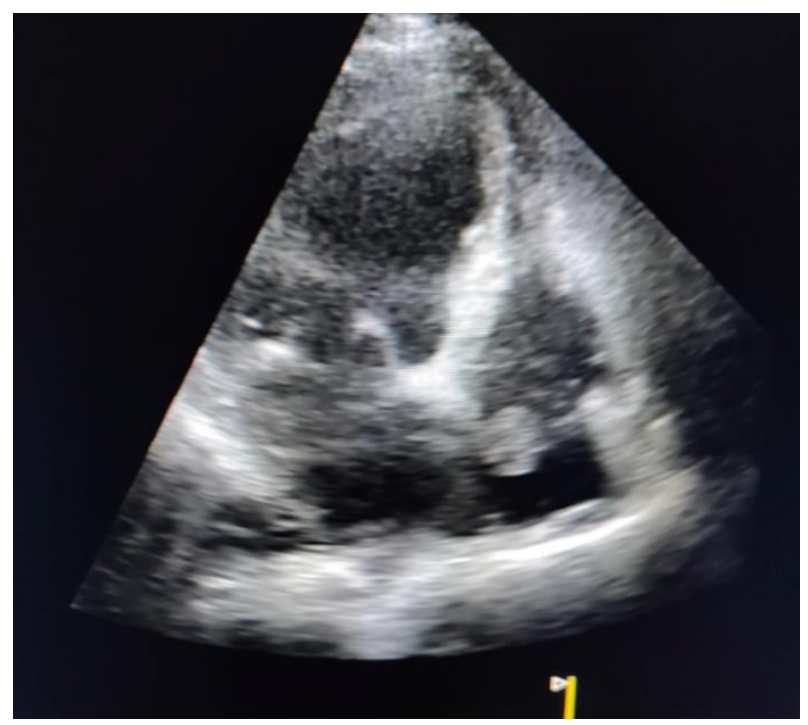

Figure A. Tranthoracic echo image of myxoma

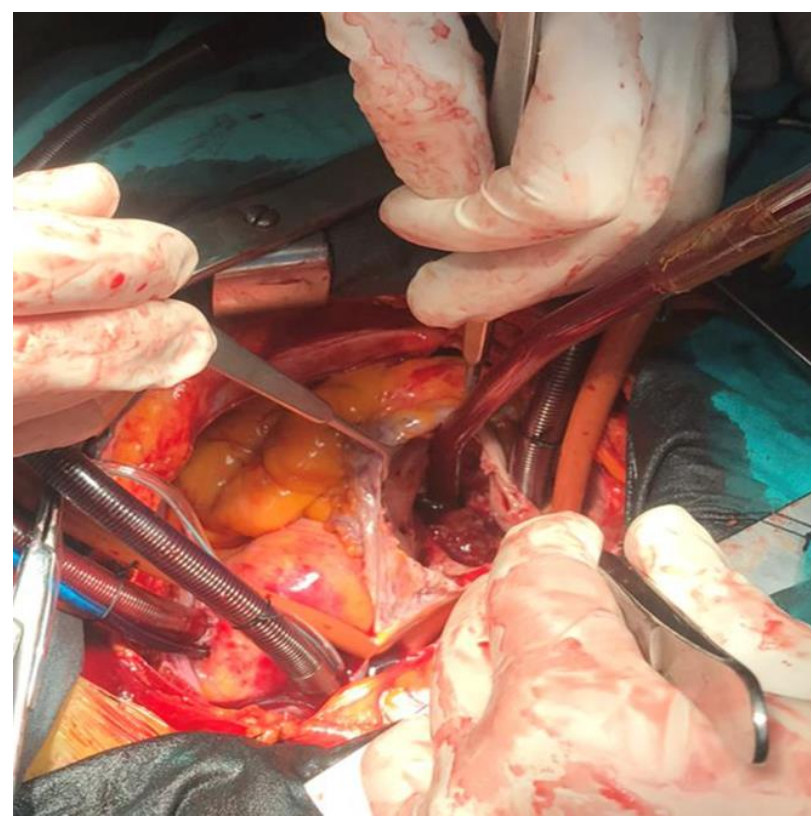

Figure B. Intraoperative view of Myxoma

\section{Discussion}

The myxoma is a primary benign cardiac tumor whose etiology is mostly unknown, adhering to the left side of the heart with a pedicle. Although it is suggested that myxomas develop from thrombus, these tumors are thought to originate from embryonal mesenchymal cells. Myxomas are divided into two as sporadic and familial form. Although it is the most common sporadic form, the family form has also been reported at a rate of 7\%. (Sun and Wang 2008, Camm et al. 2009; Kaya et al. 2014;)

It is known that there is a correlation between myxoma size and symptoms. In addition to nonspecific symptoms such as fever, fatigue, and hemoptysis the most common symptom is with dyspnea and chest pain. Myxomas with right cardiac involvement may cause tricuspid insufficiency and right heart failure, depending on the location or deform the tricuspid valve. In addition, it has been reported that massive embolism may occur in these patients, and recurrent emboli may occur with small tumor fragments (Calejero et al. 2005, Beso and Cedo 2013).

Early diagnosis of myxoma is difficult because the symptoms of myxoma are frequently nonspecific. In patients with myxoma may hear diastolic murmur mixed with mitral stenosis during auscultation. (Camm et al, 2009). Diagnosis of myxoma is made by 2-dimensional transthoracic echocardiography in all cases. Transesophageal echocardiography gives detailed information about the localization and size of the tumor. Computed tomography and magnetic 
resonance imaging techniques can also be used for diagnosis. (Kaya et al. 2014)

The treatment of myxoma is surgical excision of the mass completely and together with the intact around tissue. The point to be considered in the operation of the patient is that the vena inferior cannula should be placed after entering the pump when necessary to avoid intraoperative tumor embolization during cannulation. Surgical excision of myxoma results in complete recovery if performed carefully. In long-term follow-up, recurrence is very very rare in these patients. (Kuroczynski et al. 2009; Scrofani et al. 2020) Recurrence is generally observed in case of insufficient resection, tumor with several orgin and familial type. (Pedro, 2008)

\section{Conclusion}

Right atrial myxoma can form a severe status after admission with symptoms of shortness of breath. Therefore, in the patient with shortness of breath and progresses or systemic/pulmoner embolic phenomenon the phsicians should be carefully and cardiac tumors should be considered. In these patients, evaluation with transthoracic echocradiography, which is a noninvasive diagnostic method, is very important and it should be remembered that these patients should be evaluated very carefully. Surgical excision should be done at an early stage after diagnosis to prevent it.

Ethics Committee Approval: Approval was received for this study from the patient.

Peer-review: Externally peer-reviewed.

Author Contributions: Concept- S.D, A.K, DesignM.Ü,K. T, Supervision- O.B Literature Review- M.F, Writing S.D, A.K, Critical Review- M.Ü, O.B, K.D.

Conflict of Interest: No conflict of interest was declared by the authors.

Financial Disclosure: The authors declared that this study hasn't received no financial support.

\section{References}

Beso VL, Cedo ZE. Secondary pulmonary embolism to right atrial myxoma. Semergen 2013; 39(7):54-56.

Calejero B, Carretero MG, Nadal OR, Montero FI. Pulmonary embolism and myxoma of right atrial. An Med Interna 2005; 22: 478-480.

Camm JA, Lüscher, FT, Serruys P, editors. The ESC Textbook of Cardiovascular Medicine 2nd edition. Oxford University Press. 2009
Castillo GJ, Silvay G. Characterization and management of cardiac tumors. Semin Cardiothorac Vasc Anesth 2010; 14:6-20.

Kaya Ö, Ermiş H, Türkkan S, Aytemur ZA, Baysal T. A Right Atrial Myxoma Mimicking Pulmonary Embolism: A Case Report. Eurasian J Pulmonol 2014; 16: 40-43.

Kuroczynski W, Peivandi AA, Ewald P, Prufer D, Heinemann M,Vahl CF. Cardiac myxomas: shortand long-term follow-up. Cradiol J 2009; 16:4474454.

Lepiller A, Chaib A, Bougouin W, Joffre J, Durand E, Salvi $S$ et al. Case report and review of a voluminous right atrial myxoma revealed by heart failure. Ann Cardiol Angeiol 2010; 59:37-39.

Pedro BR, Alejandro RM, Ricardo ZS, Sergio MV, Manuel JILI, Claudio A et al. Cardiac myxoma: clinical characterization, diagnostic methods and late surgical results. Rev Med Chil 2008; 136: 287-295.

Shapiro LM. Cardiac tumors: diagnosis and management. Heart 2001; 85:218-22.

Scrofani R, Carro C, Villa L, Botta M, Antona C. Cardiac myxoma: surgical results and 15-year clinical follow-up. Ital Heart J 2002;3: 753-758.

Sun P, Wang ZB. Familial atrial myxoma.Cardiol Young 2008; 18: 525-527.

Veicki L, Nicin S, Mihajlovic B, Kovacevic P, Susak S, Fabri M. Cardiac myxoma: clinical presentation, surgical treatment and outcome. J Buon 2010; 15:51-55 